\title{
Storage of spermatozoa in the female genital tract of the vespertilionid bat, Scotophilus heathi
}

\author{
A. Krishna and C. J. Dominic \\ Department of Zoology, Banaras Hindu University, Varanasi 221005, India
}

\begin{abstract}
Summary. Spermatozoa were observed in all parts of the genital tract in females killed in January, February, March and April although copulation occurs only until early February. The spermatozoa were arranged linearly with their heads orientated towards the epithelial lining.
\end{abstract}

\section{Introduction}

Prolonged storage of spermatozoa in the female reproductive tract is known to occur in bats of temperate regions (see Racey, 1975). Discovery of the sperm storage phenomenon in the tropical vespertilionids Tylonycteris pachypus and T. robustula (Medway, 1972) and Pipistrellus ceylonicus (Gopalakrishna \& Madhavan, 1971) indicates that prolonged hibernation, which characterizes temperate-zone species, is not an essential corollary for sperm storage. During an investigation into the reproductive cycle of Scotophilus heathi, a vespertilionid bat distributed all over India and Ceylon, it was found that spermatozoa are stored in the female reproductive tract in this species and the results are reported here.

\section{Materials and Methods}

All animals were collected, during the years 1974 to 1976 , by inserting a gummed rod into their roosting places (crevices on the walls of buildings). The specimens were identified by the Chiroptera Section of the Zoological Survey of India, Calcutta. The animals were killed soon after their arrival in the laboratory and the reproductive tracts were fixed in Bouin's fluid for $24 \mathrm{~h}$, embedded in paraffin wax and serially sectioned at $6 \mu \mathrm{m}$. The sections were stained with Mayer's haemalum and counterstained with eosin.

\section{Results}

Spermatozoa were seen in the female genital tract for the first time in early January. This fact, plus the observations that males and females roost together only between early January and early February and that torpidity in this bat is noticed in Varanasi during December and early January, indicate that copulation occurred during early January to early February. Soon after copulation, the vagina became occluded because of extensive cornification of the vaginal epithelium, and this occlusion persisted until at least the end of February, thereby probably preventing further copulation. Adult females with recently ovulated Graafian follicles were first observed on $10 \mathrm{March}$. By the last week of March, the ovaries of all adult females contained newly ovulated follicles or corpora lutea, suggesting that although copulation occurs between early January and early February, ovulation and fertilization do not occur until the first week of March. The conceptuses were first observed in mid-April and the duration of gestation (implantation to birth) is therefore approximately 90 days (mid-April to mid-July.) 
Spermatozoa were observed in all parts of the reproductive tract at various times after copulation (Table 1; Pl. 1, Figs 1-4). Some free spermatozoa were seen in the vagina, uterus, uterotubal junction and oviduct but most were characteristically arranged in the genital tract. The spermatozoa were aligned with their heads orientated towards the epithelial lining (Pl. 1, Figs 1-3). In females killed in early April, spermatozoa were also seen around blastocysts (Pl. 1, Fig. 4). The spermatozoa must therefore be stored for about $60-80$ days.

Table 1. The occurrence of spermatozoa in the female genital tract of Scotophilus heathi

\begin{tabular}{|c|c|c|c|c|c|}
\hline Month & $\begin{array}{l}\text { No. } \\
\text { of } \\
\text { bats }\end{array}$ & Vagina & Uterus & $\begin{array}{l}\text { Uterotubal } \\
\text { junction }\end{array}$ & Oviduct \\
\hline January & 6 & Free spermatozoa & $\begin{array}{l}\text { Free and attached } \\
\text { spermatozoa }\end{array}$ & $\begin{array}{l}\text { Free and attached } \\
\text { spermatozoa }\end{array}$ & Free spermatozoa \\
\hline February & 6 & No spermatozoa & $\begin{array}{l}\text { Free and attached } \\
\text { spermatozoa }\end{array}$ & $\begin{array}{l}\text { Free and attached } \\
\text { spermatozoa }\end{array}$ & Free spermatozoa \\
\hline March & 10 & No spermatozoa & $\begin{array}{l}\text { Free and attached } \\
\text { spermatozoa }\end{array}$ & $\begin{array}{l}\text { Free and attached } \\
\text { spermatozoa }\end{array}$ & $\begin{array}{l}\text { Free and attached } \\
\text { spermatozoa }\end{array}$ \\
\hline April & 4 & No spermatozoa & $\begin{array}{l}\text { Attached spermatozoa; } \\
\text { spermatozoa around } \\
\text { blastocyst }\end{array}$ & $\begin{array}{l}\text { Attached } \\
\text { spermatozoa }\end{array}$ & $\begin{array}{l}\text { Attached } \\
\text { spermatozoa }\end{array}$ \\
\hline
\end{tabular}

All attached spermatozoa were linearly arranged with their heads towards the epithelial lining.

\section{Discussion}

Prolonged storage of viable spermatozoa in the female reproductive tract occurs throughout the animal kingdom (see Racey, 1975). Among the non-mammalian vertebrates the phenomenon has been described in the guppy (Poecilia reticulata), dogfish (Scyliorhinus canicula), newt (Notopthalmus viridescens), salamander (Salamandra salamandra), several species of lizards, garter snake (Thamnophis sirtalis) and hen (Gallus domesticus) (see Racey, 1975, for references). In mammals, apart from the bats in which sperm storage in the female genital tract has been well established, the phenomenon has been demonstrated in the bitch (Doak, Hall \& Dale, 1967), mice (Ullman, 1976) and the shrew, Blarina brevicauda (Pearson, 1944). An examination of the relationship that is established between spermatozoa and the female reproductive tract in vertebrates reveals that the stored spermatozoa remain either embedded in or in intimate contact with the epithelial lining of the storage organ. It is suggested that the secretory products elaborated by the epithelial lining of the storage organs facilitate the survival of the stored spermatozoa (see Racey, 1975).

\section{EXPLANATION OF PLATE}

Sections of the genital tract of female Indian vespertilionid bats, Scotophilus heathi.

Fig. 1. Transverse section of the uterus in March to show the arrangement of the spermatozoa with their heads orientated towards the uterine epithelium. The contour of the mass of spermatozoa and uterine contents approximates that of the uterine lumen, $\times 158$.

Fig. 2. A higher magnification of part of Fig. 1. Note the linear arrangement of spermatozoa. $\times 1155$.

Fig. 3. Transverse section of the uterotubal junction in March to show the arrangement of the stored spermatozoa. Shrinkage has occurred but the contour similarities are apparent. $\times 245$.

Fig. 4. Transverse section of the uterus in April. Spermatozoa are seen orientated towards the uterine epithelium and also around the blastocyst (arrow). $\times 325$. 

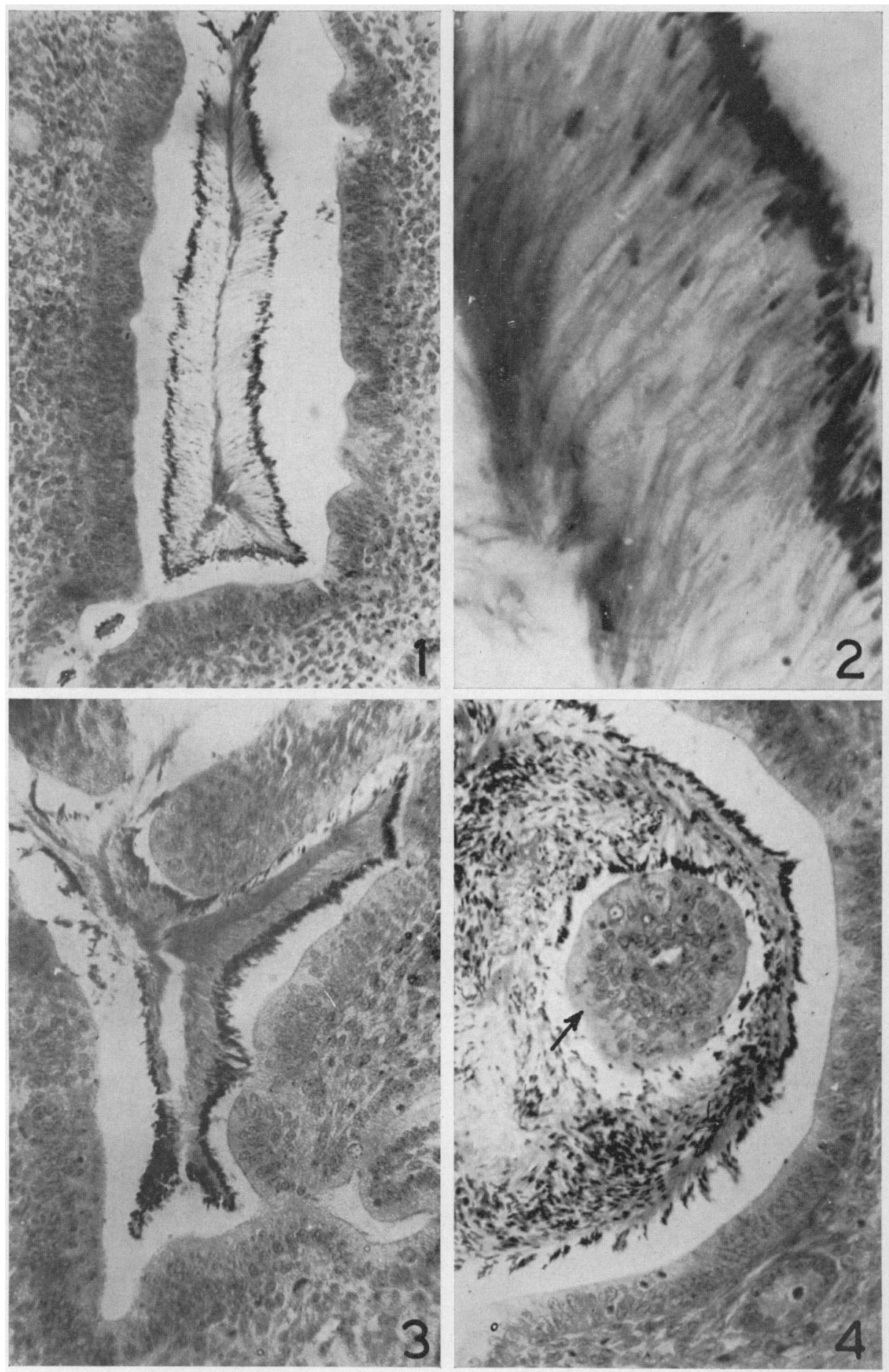
In $S$. heathi, the apparent separation of the spermatozoa and the epithelium is due to differential shrinkage because the contour of the sperm mass and uterine contents approximates that of the lumen of the storage organ (PI. 1, Figs 1 and 3). It is therefore very probable that in this species also the stored spermatozoa are in intimate contact with the epithelial lining. Close contact between spermatozoa and the uterine epithelium has been demonstrated in Pipistrellus pipistrellus (Racey \& Potts, 1970) and Tylonycteris spp. (Racey, Suzuki \& Medway, 1975) and the stored spermatozoa are known to be metabolically active. Association of spermatozoa with the epithelium of the storage organ probably protects the spermatozoa from various disintegrative factors (e.g. muscular movements of the uterus) and facilitates the transfer of metabolites.

The persistence of the vaginal plug for a considerable period after copulation and the presence of spermatozoa around the blastocysts (Pl. 1, Fig. 4) provide circumstantial evidence for prolonged survival of spermatozoa in the genital tract of female bats (see Harrison Matthews, 1937), although this has been questioned by Racey (1975). Low body temperature during hibernation is thought to facilitate sperm survival in temperate-zone bats (Hartman, 1933). Recent investigations, however, suggest that for a considerable portion of the period of sperm storage bats are metabolically active (Racey, 1975). Furthermore, it has been established that the tropical species, Tylonycteris pachypus and $T$. robustula, are heterothermic and, in the laboratory, inseminated females became hypothermic at an ambient temperature of $23-26^{\circ} \mathrm{C}$ (Medway, 1973). Bats of the species $S$. heathi also exhibit hypothermia during December, but, unlike the Tylonycteris species mentioned above, the incidence of hypothermia does not appear to coincide with the period of sperm storage.

The investigation was supported by a grant from the Council of Scientific and Industrial Research, Government of India.

\section{References}

DOAK, R.L., HALL, A. \& DALE, H.E. (1967) Longevity of spermatozoa in the reproductive tract of the bitch. J. Reprod. Fert. 13, 51-58.

Gopalakrishna, A. \& Madhavan, A. (1971) Survival of spermatozoa in the female genital tract of the Indian vespertilionid bat, Pipistrellus ceylonicus chrysothrix (Wroughton). Proc. Indian Acad. Sci. B $73,43-49$.

Harrison Matthews, L. (1937) The female sexual cycle in the British horseshoe bats Rhinolophus ferrumequinum insulanus Barrett-Hamilton and $R$. hipposideros minutus Montagu. Trans. Zool. Soc. Lond. B 23, 224-255.

HARTMAN, C.G. (1933) On the survival of spermatozoa in the female genital tract of the bat. $Q$. Rev. Biol. 8 , 185-193.

Medway, LoRd (1972) Reproductive cycles of the flatheaded bats Tylonycteris pachypus and $T$. robustula (Chiroptera: Vespertilionidae) in a humid equatorial environment. Zool. J. Linn. Soc. 51, 33-61.

MEDWAY, LORD (1973) Hypothermia in flat-headed bats
(Chiroptera, Vespertilionidae: genus Tylonycteris). Mammalia 37, 646-653.

RACEY, P.A. (1975) The prolonged survival of spermatozoa in bats. In The Biology of the Male Gamete, pp. 385-416. Eds J. G. Duckett \& P. A. Racey. Academic Press, London.

RaCeY, P.A. \& Potts, D.M. (1970) The relationship between stored spermatozoa and the uterine epithelium in the Pipistrelle bat (Pipistrellus pipistrellus). J. Reprod. Fert. 22, 57-63.

Racey, P.A., Suzuki, F. \& Medway, LoRd (1975) The relationship between stored spermatozoa and the oviducal epithelium in bats of the genus Tylonycteris. In The Biology of Spermatozoa, pp. 123-133. Eds E. S. E. Hafez \& C. G. Thibault. S. Karger, Basel.

Pearson, O.P. (1944) Reproduction in the shrew (Blarina brevicauda Say). Am. J. Anat. 75, 39-93.

UllmaN, S.L. (1976) Anomalous litters in hybrid mice and the retention of spermatozoa in the female tract. J. Reprod. Fert. 47, 13-18.

Received 13 March 1978 